\title{
Toxicidade e acúmulo de flúor em hortaliças nas adjacências de uma fábrica de alumínio
}

\author{
Bruno Francisco Sant’Anna-Santos ${ }^{1,2}$ e Aristéa Alves Azevedo ${ }^{1}$
}

Recebido em 18/02/2010. Aceito em 30/09/2010

\begin{abstract}
RESUMO - (Toxicidade e acúmulo de flúor em hortaliças nas adjacências de uma fábrica de alumínio). Com o objetivo de avaliar o potencial de acumulação de flúor e o percentual deste elemento removido pela lavagem, quatro espécies de hortaliças foram expostas em área poluída. Spondias dulcis foi utilizada como bioindicadora de reação e apresentou sintomas típicos em resposta ao poluente. Somente a salsa apresentou sintomas. Apesar de aparentemente sadias, as folhas das outras espécies utilizadas para estudos microscópicos, exceto da cebolinha, evidenciaram alterações na superfície, principalmente associados aos estômatos. Houve redução na espessura do limbo, mais acentuada no manjericão e na cebolinha, havendo formação de tecido de cicatrização na couve e condensação do conteúdo das células epidérmicas na salsa. As folhas subuladas e eretas da cebolinha favoreceram o menor acúmulo do poluente; já na salsa, as folhas laminares, recortadas e paralelas ao solo contribuíram para a maior retenção. A lavagem das folhas removeu 34,1 e 73,9\% do flúor na cebolinha e na salsa, respectivamente, indicando que a maior parte do poluente encontrava-se internamente na cebolinha e externamente na salsa. $\mathrm{O}$ cultivo destas hortaliças em áreas poluídas por flúor é inadequado, pois os teores do poluente estão acima do recomendado para o consumo, mesmo após a lavagem das folhas.
\end{abstract}

Palavras-chave: anatomia foliar, Allium schoenoprasum, Brassica oleracea, Ocimum basilicum, Petroselinum crispum

\begin{abstract}
Toxicity and fluoride accumulation in herbs grown in the vicinity of an aluminum plant). To assess fluoride accumulation potential and the percentage of fluoride removed by washing, four herb species were exposed to a polluted area. Spondias dulcis was used as a responsive bioindicator and showed typical fluoride response symptoms. Symptoms were observed only in parsley. Although apparently healthy, the leaves of the remaining herbs, except for chives, showed surface damage associated mainly with stomata when observed under the microscope. A reduction in leaf thickness was also observed, most prominently in basil and chives. Scar tissue was observed in kale, and a retraction of the protoplast of the epidermal cells was observed in parsley. The subulate, erect leaves of chives accumulated less fluoride; on the other hand, parsley leaves are laminar, lobed and parallel to the soil, which contributed to higher pollutant retention. Washing the leaves removed 34.1 and $73.9 \%$ of the fluoride on chives and parsley, respectively, indicating that for chives, most of the pollutant was found inside the leaves, while for parsley, the pollutant was located on the outside. Growing these herbs in fluoridepolluted areas is not recommended, since pollutant percentages are above levels recommended for consumption, even after washing the leaves.

Key words: leaf anatomy, Allium schoenoprasum, Brassica oleracea, Ocimum basilicum, Petroselinum crispum
\end{abstract}

\section{Introdução}

O flúor, poluente atmosférico extremamente fitotóxico (Weinstein \& Davison 2003), pode ser liberado na atmosfera durante a produção de alumínio, tijolos, vidros e aço (Fornasiero 2001). Nas plantas, o flúor penetra principalmente pela folha (Fortes et al. 2003) que é o órgão mais estudado para avaliação do impacto causado por poluentes (Silva et al. 2000) e o principal sítio de acumulação deste elemento (Ledbetter et al. 1960). Entretanto, algumas espécies vegetais são capazes de acumular grandes quantidades de flúor em suas folhas sem apresentar injúrias visuais (Arndt et al. 1995), o que torna o uso apenas da sintomatologia inadequado na avaliação do efeito de substâncias fitotóxicas (Tuffi Santos et al. 2007). Em resposta ao flúor, por exemplo, danos microscópicos drásticos em folhas visualmente sadias já foram relatados em Brachiaria brizantha, B. decumbens (Pita-Barbosa et al. 2009); Magnolia ovata (Sant Anna-Santos et al. 2007), Joannesia princeps e Spondias dulcis (Sant'Anna-Santos \& Azevedo 2007). Assim, análises microscópicas são essenciais e podem auxiliar no diagnóstico precoce da injúria antes do surgimento de sintomas visíveis além de auxiliar no esclarecimento os mecanismos de fitotoxidade (Silva et al. 2000; Sant'Anna-Santos et al. 2006a; Sant'Anna-Santos et al. 2007; Sant'Anna-Santos \& Azevedo 2007).
Em espécies que acumulam flúor sem apresentar danos visíveis o consumo de folhas contaminadas oferece risco considerável a saúde humana (Peixoto et al. 2005) pois pode aumentar significativamente a absorção e acúmulo desse elemento e causar fluorose dentária e-ou óssea, além de efeitos mutagênicos (Mohamed \& Chandler 1977; WHO 2002; Jones et al. 2005). O flúor ingerido é absorvido rapidamente pelo trato gastrointestinal, carregado pela corrente sanguínea e excretado via sistema renal ou é incorporado aos tecidos calcificados, sendo que a maior parte do elemento incorporado ao esqueleto e aos dentes tem uma meia-vida biológica de vários anos (WHO 2002).

Zhou et al. (2006) observaram elevados teores do flúor em hortaliças cultivadas nas proximidades de uma fonte emissora de poluentes na China desaconselhando, desta forma, o cultivo de plantas para o consumo animal na área. No Brasil, a cidade de Ouro Preto, localizada a sudeste da zona mais povoada e industrializada do Estado de Minas Gerais, denominada Zona Metalúrgica (Divan Junior et al. 2007), está sujeita aos impactos do flúor, oriundos de uma fábrica de alumínio, conforme resultados obtidos por meio de experimentos de biomonitoramento com plantas (Divan Junior et al. 2007; Divan Junior et al. 2008). Algumas espécies da flora nativa apresentaram sinais claros de contaminação por flúor, atingindo níveis superiores a 1000 $\mu \mathrm{g} \mathrm{g}^{-1}$ do poluente (Divan Junior et al. 2008) que, segundo

\footnotetext{
1 Universidade Federal de Viçosa, Departamento de Biologia Vegetal, Viçosa, MG, Brasil

2 Autor para correspondência: brunoufmg@ufmg.br
} 
Treshow \& Anderson (1989), ocorrem próximo a fontes emissoras sem controle de suas emissões.

Considerando a presença de hortas em residências de vilas situadas nas adjacências de uma fonte emissora de poluentes objetivou-se: avaliar o potencial acumulador de flúor em espécies de hortaliças utilizadas pelos moradores da região; avaliar a fitotoxidade causada pelo poluente, nas espécies estudadas, a partir da associação de parâmetros macro e microscópicos e, determinar a percentagem de flúor removida pela lavagem das folhas com água. Testaram-se as seguintes hipóteses: hortaliças expostas a fontes emissoras de flúor acumulam o poluente e a lavagem das folhas antes do consumo não promove a remoção do poluente para quantidades aconselháveis a sua ingestão.

\section{Material e métodos}

Foram utilizadas as espécies Allium schoenoprasum L. (Liliaceae), Brassica oleracea var. acephala DC. (Brassicaceae), Ocimum basilicum L. (Lamiaceae) e Petroselinum crispum (Mill.) Mansf. (Apiaceae), popularmente conhecidas como cebolinha, couve, manjericão e salsinha, respectivamente.

Para a obtenção das plantas, sementes certificadas das hortaliças foram semeadas em substrato comercial, em bandejas de isopor desinfestadas (com água sanitária) em ambiente protegido. Cerca de 15 dias após a germinação, quando as plântulas atingiram cerca de $30 \mathrm{~mm}$, foram transplantadas para vasos de polipropileno com $200 \mathrm{~mm}$ de largura, $200 \mathrm{~mm}$ de profundidade e $600 \mathrm{~mm}$ de comprimento.

Spondias dulcis Forst. F. (Anacardiaceae) foi utilizada como espécie referência, na condição de bioindicadora ativa de níveis fitotóxicos de flúor na atmosfera, haja vista que os sintomas macro e microscópicos em resposta ao poluente já foram descritos em laboratório (Silva et al. 2000; Sant'Anna-Santos \& Azevedo 2007) e na mesma área do presente estudo (Sant'Anna-Santos 2008).

As plantas de $S$. dulcis foram obtidas a partir de propagação seminífera de um único indivíduo adulto situado nas adjacências do Viveiro do Parque Estadual do Rio Doce-MG (VPERD), a $280 \mathrm{~m}$ de altitude e localização determinada pelas coordenadas geográficas de $19^{\circ} 57^{\prime} 04^{\prime \prime}$ de latitude sul e $42^{\circ} 50^{\prime} 27$ " de longitude oeste, mapeado mediante utilização do sistema de posicionamento global (modelo GPS II plus, Garmin Ltd., Hampshire, UK),

As sementes foram plantadas em sacos plásticos de $10 \mathrm{~cm}$ de diâmetro por $22 \mathrm{~cm}$ de comprimento contendo mistura de solo, moinha de carvão e adubo, composição usualmente utilizada no VPERD. Com dois meses de idade, as mudas foram transferidas para vasos de $2,6 \mathrm{dm}^{3}$ e aclimatadas durante dois meses, em ambiente não poluído, na Unidade de Crescimento de Plantas (UCP) da Universidade Federal de Viçosa (UFV).

Todas as plantas receberam solução nutritiva de Hoagland a 0,25 de força (Hoagland \& Arnon 1950) a cada cinco dias, seguindo metodologia proposta por Silva et al. (2000), até atingirem cerca de cinco meses de idade. $\mathrm{O}$ experimento foi conduzido em blocos aos acaso, com quatro repetições por tratamento.

As plantas foram expostas no campo no período 27/09/08 a 06/10/08. As mudas de $S$. dulcis foram dispostas em estantes a 1,5 $\mathrm{m}$ do solo, conforme recomendado por Divan Junior et al. (2007) para execução de biomonitoramento ativo. Já os vasos contendo as hortaliças foram dispostos no chão, visando simular as condições de cultivo em hortas.

Seguindo metodologia adotada por Divan Junior et al. (2007), o experimento foi conduzido em dois municípios, Ouro Preto e Viçosa, ambos localizados no estado de Minas Gerais, Brasil, denominados área poluída (AP) e estação referência (ER), respectivamente. $\mathrm{Na} \mathrm{AP}$, as plantas foram expostas às imissões de poluentes da fábrica de alumínio em área aberta de uma residência na Vila dos Engenheiros, a 0,78 km da fonte emissora, localizada a $1101 \mathrm{~m}$ de altitude, nas coordenadas geográficas de $20^{\circ} 24^{\prime} 09,7^{\prime \prime}$ de latitude sul e $43^{\circ} 31^{\prime} 14,8^{\prime \prime}$ de longitude oeste. Na AP, de acordo com Köppen, o clima é do tipo tropical de altitude e classificado como $\mathrm{Cwb}$, caracterizado por verões chuvosos e invernos secos (Köppen 1948). A concentração de flúor no ar em Ouro Preto (AP), atingiu, durante os anos de 2000 a 2002, valores máximos entre 6,22 e 12,87 $\mathrm{mg} \mathrm{m}^{-3}$. Contudo, os limites relevantes de qualidade de ar adotados em muitos países para proteção de espécies sensíveis situam-se entre 0,3 e 0,5 $\mathrm{g} \mathrm{m}^{-3}$ de HF (VDI 1989; EU 2001; MOE 2005). Já em relação ao $\mathrm{SO}_{2}$, durante os três anos de monitoramento, níveis baixos deste poluente foram registrados, em conformidade com os padrões vigentes, justificando ser o flúor o poluente alvo do presente estudo.

$\mathrm{Na}$ ER, as plantas foram dispostas na UCP, em área livre da poluição (Divan Junior et al. 2007), a $78 \mathrm{Km}$ da fonte emissora, a $649 \mathrm{~m}$ de altitude e localizada pelas coordenadas geográficas de $20^{\circ} 45^{\prime} 20^{\prime}$ " de latitude sul e $42^{\circ} 52^{\prime} 40^{\prime \prime}$ de longitude oeste. Em Viçosa (ER), de acordo com Köppen, o clima é do tipo tropical de altitude e classificado como Cwb, caracterizado por verões brandos (Köppen 1948).

Diariamente, durante a exposição das plantas no campo na AP e ER, foram feitas observações para acompanhar o aparecimento e a localização das injúrias relacionadas à ação do flúor, conforme proposto por Silva et al. (2000). A exposição no campo teve duração de nove dias, tempo utilizado por Divan Junior et al. (2007) na mesma área ao expor gramíneas bioindicadoras a poluição atmoférica. Também foram coletadas amostras foliares para análises microscópicas e quantificação de flúor.

Todas as amostras para análise microscópica foram coletadas em folhas sem sinais visíveis de injúria. As amostras foliares das hortaliças foram fixadas em solução de glutaraldeído (2,5\%), paraformaldeído (4\%) em tampão cacodilato de sódio $\mathrm{pH}$ 7,2 acrescido de cloreto de cálcio $5 \mathrm{mM}$ (Karnovsky 1965). Posteriormente, as amostras foram lavadas em tampão cacodilato e desidratadas em série etílica crescente e incluídas em glicol metacrilato (Historesin, Leica Instruments, Heidelberg, Alemanha).

Para análise da estrutura foliar, cortes transversais ( $5 \mu \mathrm{m}$ de espessura) realizados em micrótomo rotativo (modelo RM2155, Leica Microsystems Inc., Deerfield, USA) foram corados em azul de Toluidina/ $\mathrm{pH}=4,0$ (O’Brien \& McCully 1981) e montados em água. Para observação e documentação fotográfica foi utilizado um microscópio de luz (modelo Olympus AX70TRF, Olympus Optical, Tóquio, Japão) com sistema U-Photo. Para análise micromorfométrica foi feita a mensuração da espessura do limbo (Lim), do parênquima paliçádico (Pp) e do lacunoso (Pl) e da altura das células epidérmicas das faces adaxial (Ead) e abaxial (Eab), na porção da lâmina foliar entre a margem e a nervura mediana. De cada uma das repetições (planta), uma amostra foliar foi seccionada. De cada amostra, foram confeccionadas três lâminas histológicas contendo 18 cortes e, em cada lâmina, três cortes foram fotografados e geradas imagens digitais. De cada imagem digital foram realizadas três medições da espessura de cada um dos tecidos (Lim, Pp, Pl, Ead e Eab) gerando uma média, utilizando-se o software ANATI QUANTI, versão 2.0 para Windows ${ }^{\circledR}$ (Aguiar et al. 2007).

Para análise da micromorfologia foliar, as amostras previamente fixadas foram secas ao ponto crítico em equipamento apropriado (modelo CPD 020, Bal-Tec, Balzers, Liechtenstein). Após cobertura metálica com ouro (Metalizador modelo FDU010, Bal-Tec, Balzers, Liechtenstein), o material vegetal foi analisado ao microscópio eletrônico de varredura e as imagens registradas utilizando-se uma câmera digital acoplada (modelo JSMT200, Jeol Co., Tokyo, Japão).

Para a quantificação do teor do flúor na matéria seca, todas as folhas de cada uma das repetições foram previamente secas em estufa, a $70^{\circ} \mathrm{C}$, e reduzidas a partículas com dimensões inferiores a $0,1 \mathrm{~cm}$, em moinho do tipo Wiley. Posteriormente, alíquotas de $0,5 \mathrm{~g}$, de cada repetição, foram submetidas à extração em ácido perclórico $0,1 \mathrm{M}$ (Garcia-Ciudad et al. 1985), utilizando-se o ajustador de força iônica (Larsen \& Widdowson 1971), para determinação potenciométrica do teor de fluoreto, através de eletrodo íon seletivo. Nas hortaliças, quatro indivíduos, de cada espécie, foram expostos, na $\mathrm{AP}$ e ER, para quantificação da percentagem do poluente removido pelo processo de lavagem em água, durante 15 minutos, segundo protocolo adotado por Zhou et al. (2006). Esse procedimento verificou se o processo de lavagem, que antecede o consumo de folhosas, remove quantidade considerável do poluente. Os teores de flúor nas amostras lavadas foram comparados com os valores encontrados nas amostras não submetidas à lavagem, sendo a diferença observada considerada como a quantidade de flúor removido pelo procedimento.

O delineamento utilizado foi o de blocos ao acaso e os dados obtidos referentes à quantificação de flúor e análise micromorfométrica foram submetidos à análise de variância. Quando a hipótese de nulidade foi rejeitada, diferenças significativas entre as amostras foram determinadas pelo teste de Tukey, a $5 \%$ de probabilidade. 


\section{Resultados e discussão}

Após nove dias de exposição na área poluída (AP), as folhas de A. schoenoprasum, O. basilicum, B. oleraceae var. acephala apresentaram aspecto visual semelhante ao das plantas expostas na estação referência (ER), ambiente não poluído. No entanto, em P. crispum as folhas apresentavam cloroses e pequenos pontos necróticos homogeneamente distribuídos pela lâmina. Em S. dulcis, espécie referência, necroses apicais e marginais surgiram aos cinco dias de exposição das plantas expostas na $\mathrm{AP}$, em contraste com $o$ aspecto verde e brilhante das folhas nas plantas na ER. Os sintomas observados em $S$. dulcis são idênticos aos registrados em experimentos conduzidos em laboratório (Silva et al. 2000) e em campo (Sant'Anna-Santos 2008) e típicas em resposta ao flúor (Ardnt et al. 1995), indicando a presença do poluente em níveis fitotóxicos na atmosfera. Apesar dos sintomas observados em $P$. crispum não serem semelhantes aos registros fotográficos disponíveis na literatura da fitotoxidez por flúor (Ardnt et al. 1995; Fornasiero 2001; Fortes et al. 2003; Weinstein \& Davison 2003; 2004; Mezghani et al. 2005; Pita-Barbosa et al. 2009; Sant'AnnaSantos et al. 2007), pode haver variação na sintomatologia entre espécies vegetais distintas, conforme observado por Weinstein \& Davison (2004) e pode haver, além da presença do flúor, outros poluentes cuja interação pode resultar em sintomatologia diversa da típica para flúor.

Ao microscópio eletrônico de varredura (MEV), a superfície foliar das hortaliças avaliadas também apresenta variações (Figs. 1-4). Em A. schoenoprasum, as células

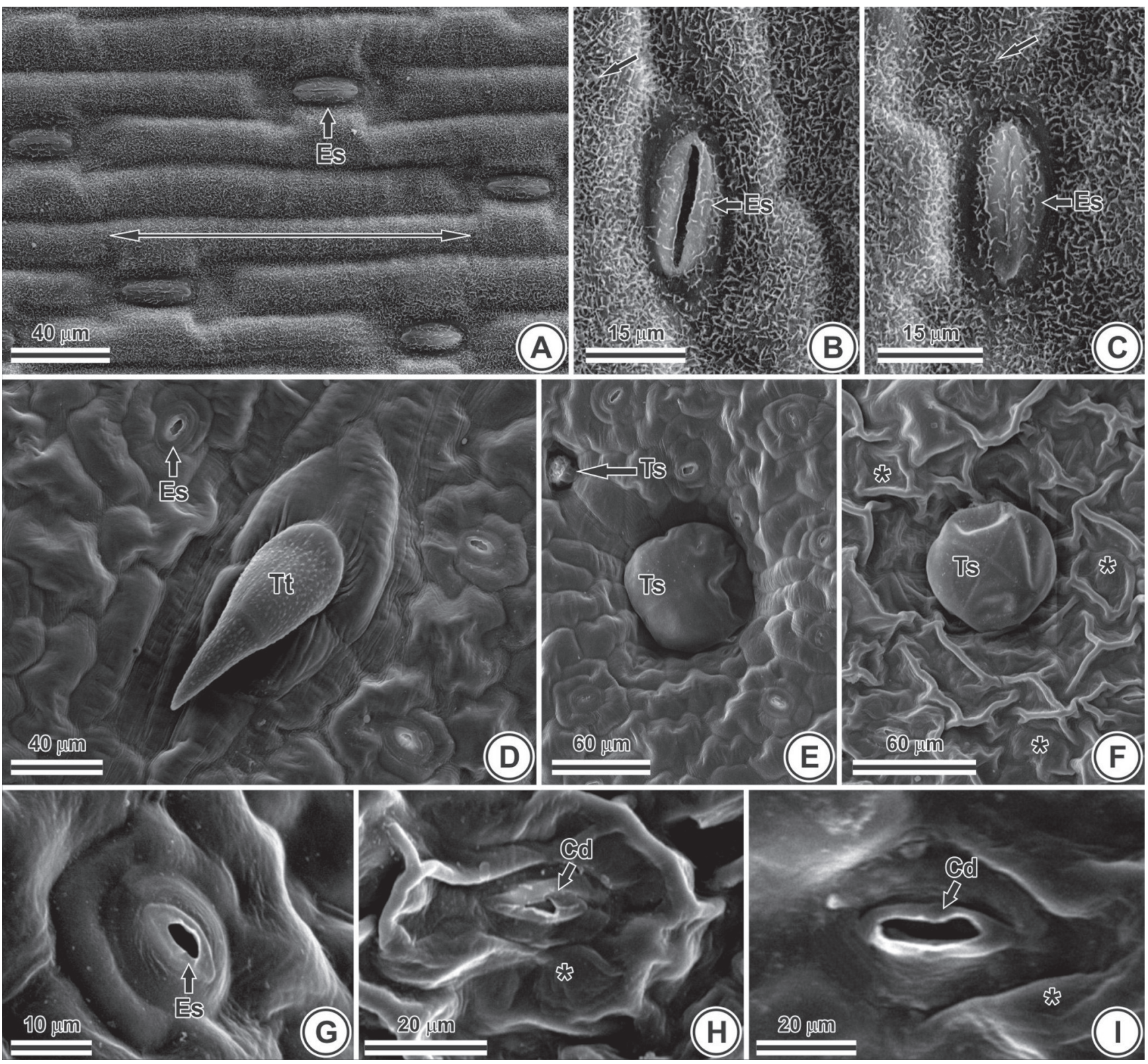

Figura 1. Eletromicrografias de folhas de Allium schoenoprasum L. (A-C) e Ocimum basilicum L. (D-I). A-B, D-E, G. Estação referência. C, F, H-I. Área poluída. Célula alongada $(\leftrightarrow)$, ceras em placas $(\rightarrow)$, tricoma tector $(\mathrm{Tt})$ e secretor $(\mathrm{Ts})$, estômato (Es), relevo cuticular $(*)$ e crista danificada $(\mathrm{Cd})$. 
epidérmicas são alongadas, os contornos das paredes anticlinais são retos (Fig. 1A) e as ceras epicuticulares estão dispostas em placas e distribuídas por toda superfície foliar, inclusive sobre os estômatos (Fig. 1B). Em O. basilicum, a epiderme, de ambas as faces da folha é repleta de tricomas tectores (Fig. 1D) e secretores (Fig. 1E) e de estômatos (Figs. 1D-E, G). B. oleracea var. acephala possui, também, folhas anfiestomáticas mas é desprovida de apêndices epidérmicos (Figs. 2A, G, I). Em P. crispum, estrias cuticulares são evidentes ao redor dos estômatos (Figs. 3A, F) e papilas estão presentes na região das nervuras (Fig. 4A, C). A partir da análise ao MEV observou-se que, em resposta ao flúor, excetuando-se $A$. schoenoprasum (Fig. 1C), porções foliares visualmente sadias das espécies de hortaliças apresentavam danos microscópicos consideráveis. A ausência de danos em A. schoenoprasum pode estar relacionada à proteção conferida pela densa cobertura de ceras epicuticulares, inclusive sobre as células estomáticas (Fig. 1), conforme observado por Chaves et al. (2002) ao comparar Chloris gayana e $\mathrm{Pa}$ nicum maximum. Em C. gayana, a maior proporção de cera pode estar relacionada com a maior resistência à poluição por flúor. Em $O$. basilicum houve alteração no relevo cuticular (Fig. 1F) e na estrutura dos estômatos (Figs. 1H-I). Na superfície adaxial das folhas de B. oleracea var. acephala (Fig. 2B), principalmente na proximidade dos estômatos (Figs. 2C-E) houve erosão de partículas de cera epicuticular. Aglomerados de ceras erodidas recobriram algumas áreas da superfície foliar (Fig. 2F). Na face abaxial, extensos trechos
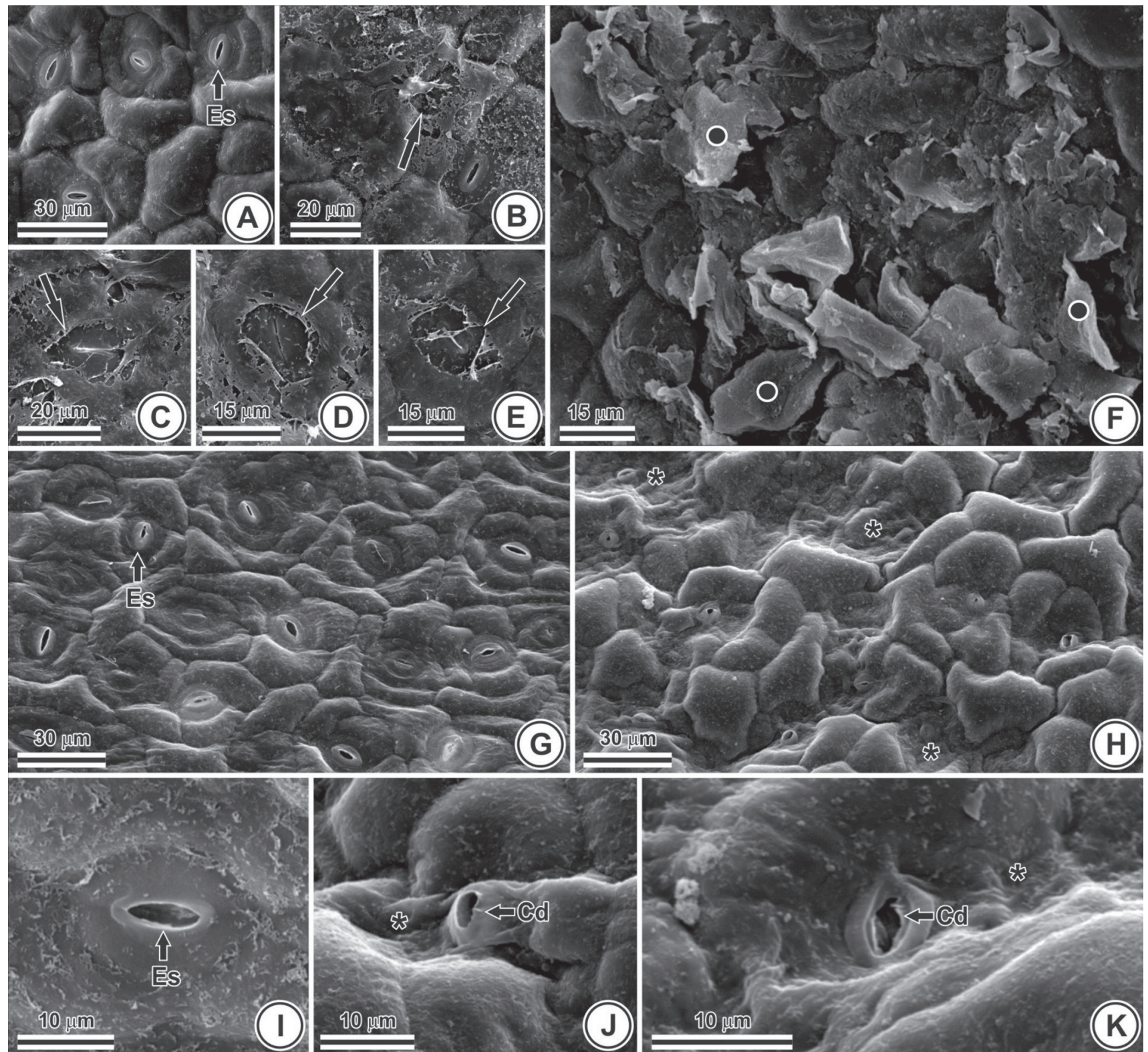

Figura 2. Eletromicrografias de folhas de Brassica oleracea var. acephala DC (faces adaxial (A-F) e abaxial (G-K)). A, G, I. Estação referência. B-F, H, J-K. Área poluída. Estômatos (Es), erosão de partículas $(\rightarrow)$ e placas $(\circ)$ de ceras, relevo cuticular alterado $(*)$ e crista danificada $(\mathrm{Cd})$. 

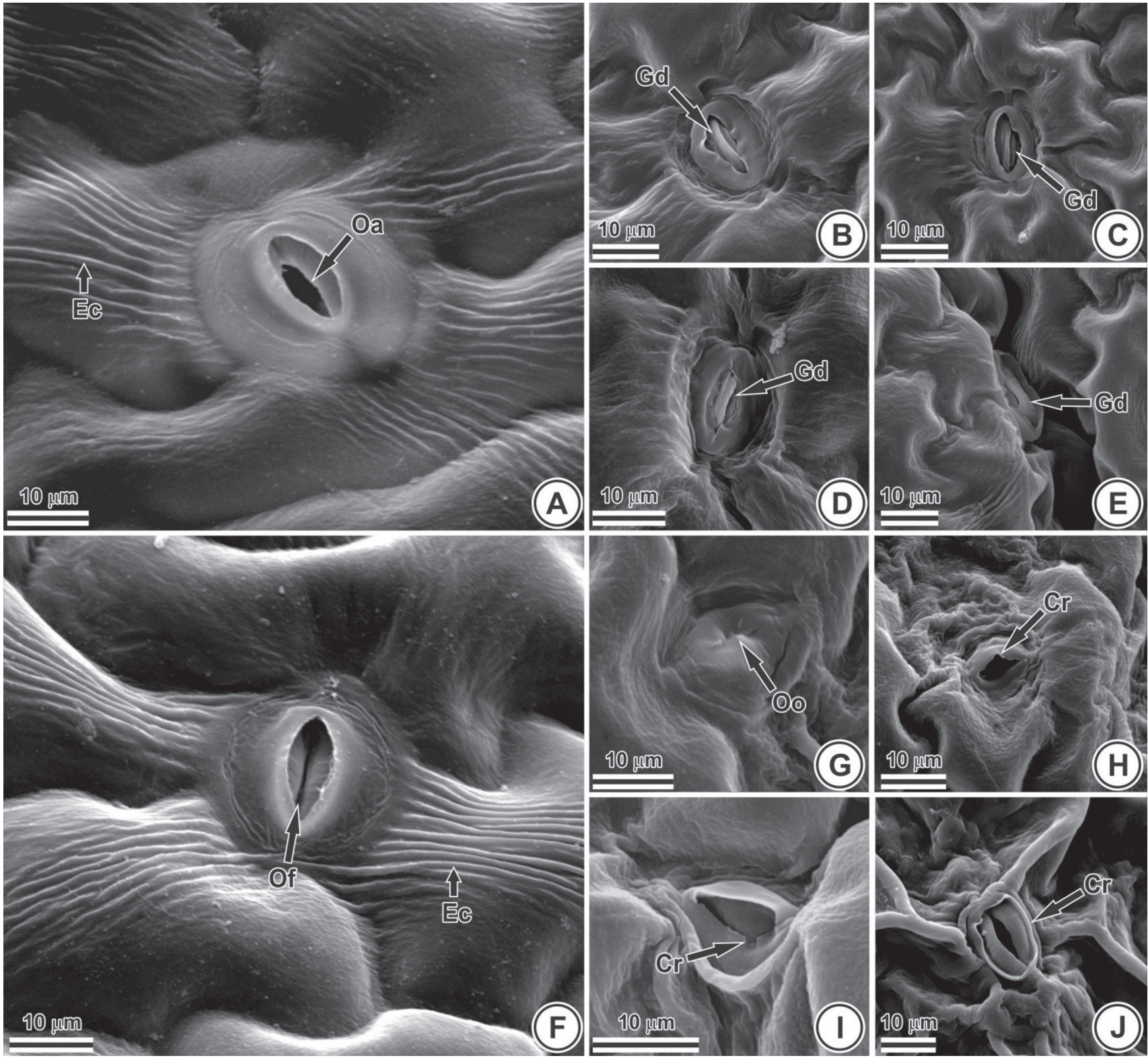

Figura 3. Eletromicrografias de folhas de Petroselinum crispum (Mill.) Mansf. (faces adaxial (A-E) e abaxial (F-J)). A e F. Estação referência. B-E,G-J. Área poluída. Estrias (Ec), ostíolo aberto (Oa) ou fechado (Of), ostíolo obliterado (Oo), célula-guarda danificada (Gd) e crista rompida $(\mathrm{Cr})$.

apresentavam alterações no relevo cuticular (Fig. 2H), em geral, nas adjacências de estômatos cujas cristas estavam danificadas (Figs. 2J-K). Em P. crispum, os danos também estavam associados aos estômatos, em ambas as faces da folha (Fig. 3); na face adaxial, houve alteração no relevo cuticular e na estrutura das células-guarda (Figs. 3B-E) e, na face abaxial, a perda da arquitetura da crista estomática obliterou ostíolos (Fig. 3G). A ruptura da crista estomática foi parcial (Figs. 3H-J) ou total, ocasionando, no último caso, a total exposição das células-guarda (Fig. 3J). As papilas também se apresentavam retraídas (Figs. 4B, D). O flúor não se distribui uniformemente na folha, tendendo a se acumular nas áreas próximas ao ponto de entrada, onde ocorrem os maiores danos (Pushnik \& Miller 1990). De modo similar à maioria dos poluentes atmosféricos, o flúor gasoso penetra nas plantas através dos estômatos (Peixoto et al. 2005), onde foi observada a maior parte dos danos nas hortaliças expostas na AP.

Ao microscópio de luz observou-se, nas plantas de $A$. schoenoprasum, folhas subuladas com mesofilo dorsiventral formado por quatro a cinco camadas de parênquima paliçádico e três a quatro camadas de parênquima lacunoso (Fig. 5A). Em $O$. basilicum, as folhas possuem mesofilo dorsiventral formado por uma camada de parênquima paliçádico e quatro a seis camadas de parênquima lacunoso braciforme (Fig. 5C), e são anfiestomáticas (Figs. 5D-E). Em B. oleraceae var. acephala, o mesofilo dorsiventral possui arranjo mais compacto (Figs. 6A, E). Na nervura mediana, quatro a cinco 

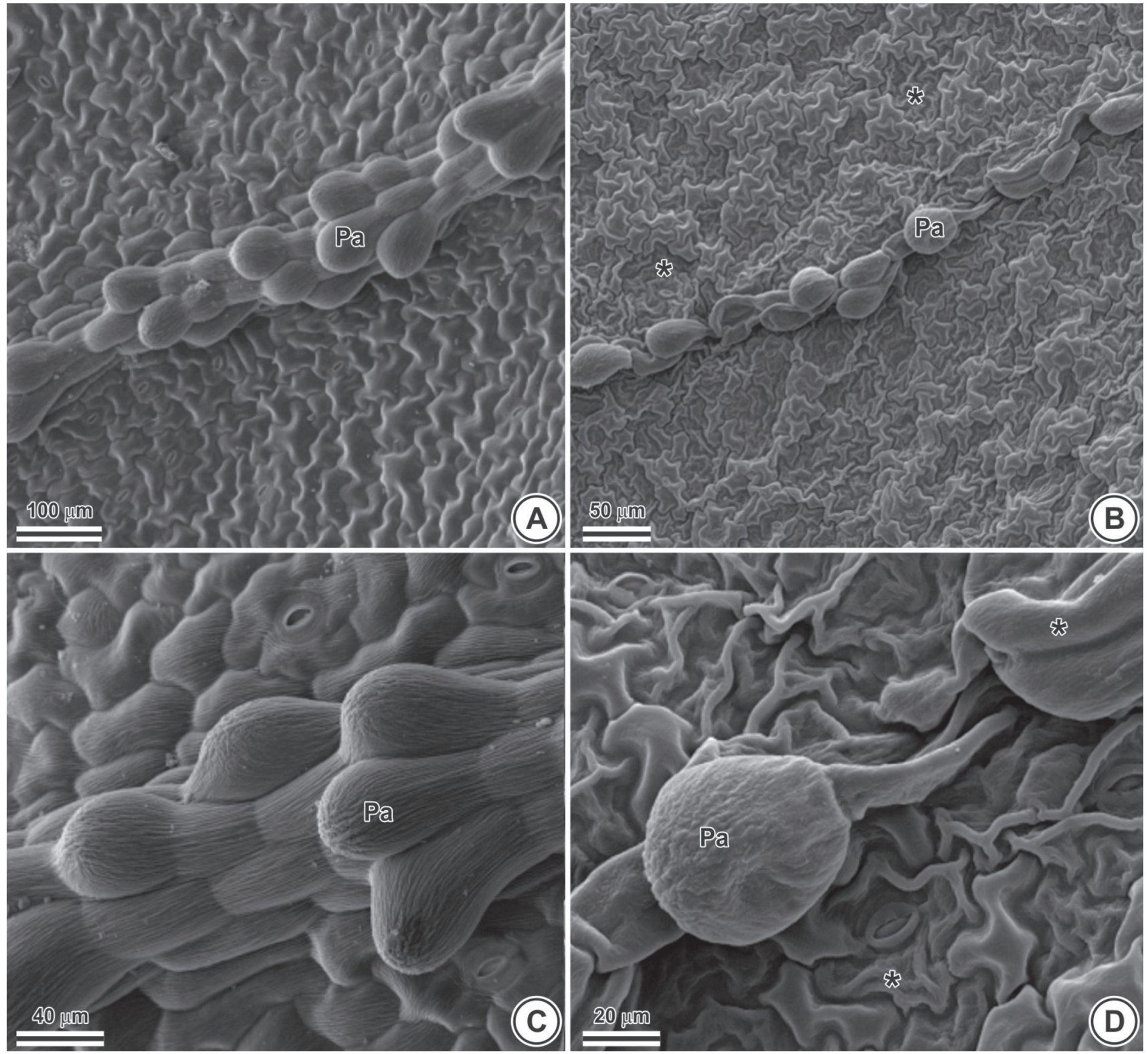

Figura 4. Eletromicrografias de folhas de Petroselinum crispum (Mill.) Mansf (face adaxial). A e C. Estação referência. B e D. Área poluída. Papilas (Pa) na região das nervuras e relevo cuticular alterado $(*)$.

camadas de fibras ocorrem entre o feixe vascular colateral e o parênquima cortical, constituído de células isodiamétricas (Fig. 6C). No mesofilo dorsiventral de P. crispum, o parênquima paliçádico se prolonga na região da nervura mediana sendo interrompido por uma calota de colênquima (Figs. 7A, C). Na nervura mediana, papilas ocorrem na face adaxial (Figs. 7A, C), sendo comum a presença de ductos secretores associados ao parênquima cortical voltado para a face abaxial da folha (Figs. 7A, E). Os estômatos também estão presentes em ambas as faces da folha (Figs. 7G, I). As folhas das plantas expostas na AP, apesar de aparentemente sadias, apresentaram danos estruturais em todas as espécies de hortaliças estudadas (Figs. 5-7). Nas espécies estudadas foi verificada redução na espessura da lâmina foliar $(\mathrm{p}<0,05)$ :
A. schoenoprasum, $28,2 \%$; O. basilicum, 33,0\%; B. oleraceae var. acephala, $20,7 \%$ e P. crispum, 14,7\% (Fig. 8). Em todas as hortaliças, não houve redução significativa na espessura da epiderme nas plantas expostas na AP (Fig. 8), quando comparadas com as da ER.

Em B. oleraceae var. acephala e P. crispum, as injúrias ocorreram, também, na nervura mediana (Figs. 6 e 7). Em B. oleraceae var. acephala, houve a indução de hiperplasia de células do mesofilo e formação de um tecido de cicatrização constituído por células volumosas e de parede celular espessada (Figs. 6B, F-J). A formação do tecido de cicatrização resulta da formação de novas células a partir da capacidade proliferativa do parênquima (Dickison 2000), sendo observada em resposta ao flúor (Azevedo 1995), chuva 


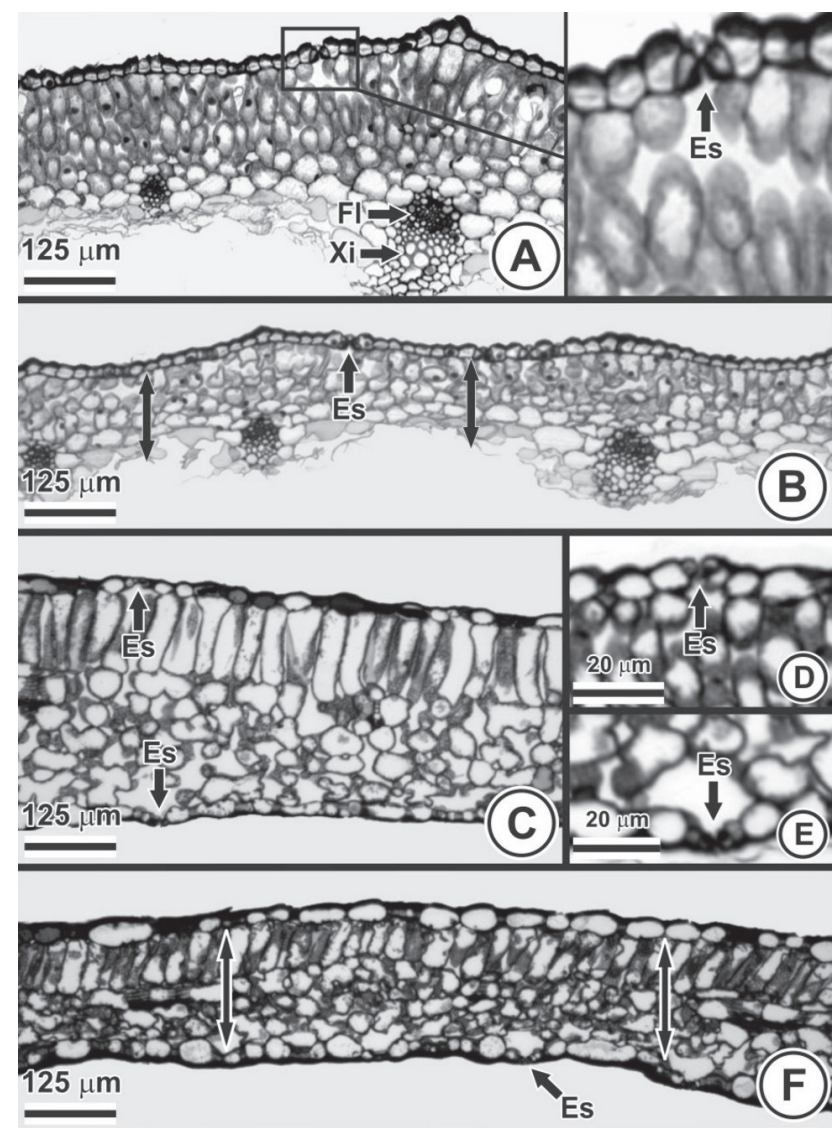

Figura 5. Anatomia foliar de Allium schoenoprasum L. (A-B) e Ocimum basilicum L. (C-F). (secções transversais). A, C-E. Estação referência. B e F. Área poluída. Estômatos (Es), espessura do mesofilo ( $\uparrow$ ), xilema (Xi) e floema (Fl).

ácida (Silva et al. 2005; Sant'Anna-Santos et al. 2006b), microorganismos (Dickison 2000) e herbicidas (Tuffi-Santos et al.2008; 2009). No tecido de cicatrização houve acúmulo de compostos intensamente corados de verde pelo azul de toluidina (Figs. 6H-I). Esta coloração tem sido utilizada por alguns autores como indicativo de acúmulo de compostos de natureza fenólica (Briggs et al. 2005). O acúmulo de fenóis como um mecanismo de defesa das plantas foi relatado em outras espécies vegetais expostas ao flúor (Fornasiero 2001; Chaves et al. 2002; Sant'Anna-Santos et al. 2007).

Em $P$. crispum, na região da nervura mediana, houve condensação do conteúdo celular das papilas (Fig. 7D), também observado na epiderme de Magnolia ovata, em resposta ao flúor (Sant'Anna-Santos et al. 2007). As células do parênquima cortical e do epitélio secretor dos ductos também sofreram alteração no formato (Fig. 7E). Em alguns trechos, observou-se a formação de depressões na superfície foliar (Figs. 7H, J). Os danos descritos na morfologia foliar das hortaliças ao MEV são semelhantes aos relatados na literatura em plantas expostas ao flúor (Chaves et al. 2002; Sant'Anna-Santos \& Azevedo 2007; Sant'Anna-Santos et al. 2007; Sant'Anna-Santos 2008; Pita-Barbosa et al. 2009).

$\mathrm{Na}$ ER, os teores de flúor das folhas lavadas após a coleta permaneceram estatisticamente iguais aos das folhas não lavadas ( $<<0,01)$, por se tratar de um ambiente não poluído (Divan Junior et al. 2007) e, desta forma, sem incremento do poluente como resposta a atividades antrópicas. Em geral, o conteúdo de flúor nas folhas de plantas, na maioria das espécies, em ambientes não poluídos, situa-se abaixo de 10 $\mu \mathrm{g} \mathrm{g}^{-1}$ (Weinstein 1977), em conformidade com o observado neste estudo. As folhas de todas as espécies expostas na AP acumularam flúor $(p<0,05)$ em comparação com a ER (Fig. 9). Aos nove dias de exposição na AP, as concentrações do poluente eram de aproximadamente 20,$7 ; 14,3 ; 20,8 ; 21,8 \mathrm{e}$ 25,2 vezes maiores que nas folhas das plantas da ER, em $S$. dulcis, A. schoenoprasum, O. basilicum, B. oleraceae var. acephala e $P$. crispum, respectivamente. Em experimentos de biomonitoramento realizados na mesma área com outras espécies também foi observado o acúmulo de grandes quantidades de flúor (Divan Junior et al. 2007; 2008; Sant'AnnaSantos 2008). Acréscimos elevados do poluente nas folhas, em curtos períodos de exposição, sugerem que as plantas ficaram expostas a elevados índices de flúor na atmosfera (Fornasiero 2003).

Das hortaliças avaliadas, A. schoenoprasum e P. crispum apresentaram, respectivamente, a menor e a maior quantidade de flúor (Fig. 9). As folhas subuladas e com posição mais ereta de $A$. schoenoprasum provavelmente desfavoreceram a retenção do poluente; já as folhas laminares, recortadas e paralelas ao solo de $P$. crispum contribuíram para a maior retenção do flúor. Na literatura, o ritmo de crescimento de cada genótipo (Vike 1999, Silva et al. 2000) e características como densidade da folhagem, tamanho das folhas (Weinstein \& Davison 2004) e capacidade de interceptação da superfície foliar, definida pela morfologia e configuração das folhas, têm sido relacionadas com a capacidade de retenção de poluentes (Mezghani et al. 2005).

$\mathrm{Na} \mathrm{AP}$, a lavagem removeu quantidades significativas $(\mathrm{p}<0,01)$ do poluente das folhas de todas as hortaliças avaliadas (Fig. 9). Em A. schoenoprasum, somente 34,1\% do flúor foi removido, indicando que a maior parte do poluente se encontrava internamente. Segundo Franzaring et al. (2007), isso se dá em decorrência de uma maior entrada de flúor gasoso via estômatos. Já nas hortaliças com folhas laminares, a quantidade removida de flúor pela lavagem das folhas foi de 69,$5 ; 57,9$ e 73,9\% em O. basilicum, B. oleraceae var. acephala e P. crispum, respectivamente, indicando que a maior parte do poluente se encontrava externamente, já que além de penetrar na folha, o flúor pode ficar adsorvido à superfície (Jacobson et al. 1966). O flúor acumulado externamente às folhas depende não só da deposição de partículas que contenham esse elemento como da adsorção de fluoretos gasosos $\left(\mathrm{HF}, \mathrm{SiF}_{4}, \mathrm{CFCs}\right)$ à superfície foliar (Franzaring et al. 2007).

Os danos mais severos observados na epiderme de P. crispum e B. oleraceae var. acephala refletem, provavelmente, a maior quantidade de poluente aderido à superfície foliar. Em algumas espécies vegetais existe uma relação entre o maior grau de injúria e as taxas elevadas de acúmulo do poluente 


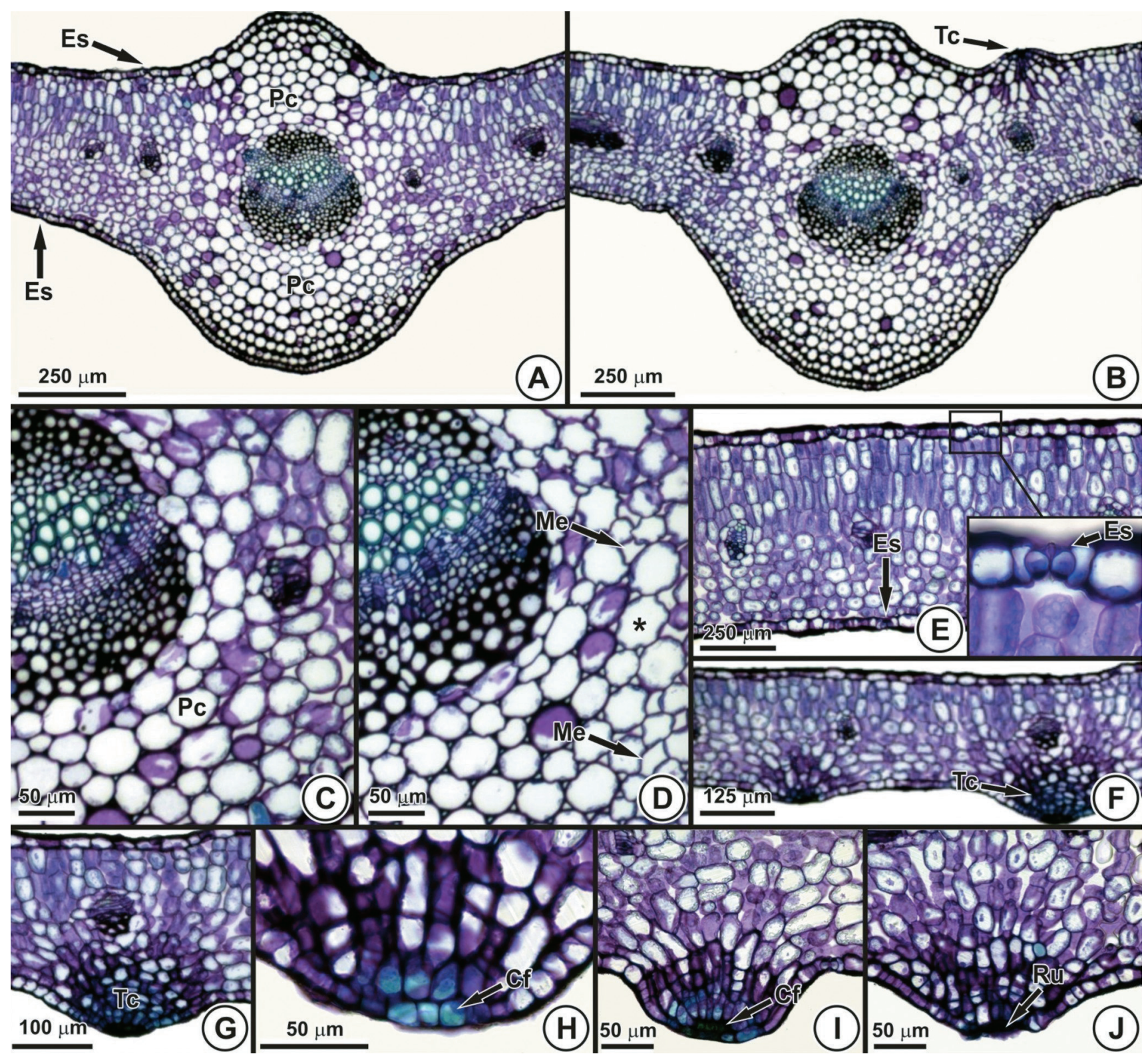

Figura 6. Anatomia foliar de Brassica oleracea var. acephala DC. (secções transversais). A, C, E. Estação referência. B, D, F-J. Área Poluída. Parênquima cortical $(\mathrm{Pc})$, estômatos $(\mathrm{Es})$, formato celular alterado $(*)$, meatos $(\mathrm{Me})$, tecido de cicatrização $(\mathrm{Tc})$, compostos fenólicos $(\mathrm{Cf})$ e ruptura $(\mathrm{Ru})$.

(Klumpp et al. 1995; Silva et al. 2000; Fornasiero 2001). No entanto, não houve redução na espessura da epiderme. A grande quantidade de cutina ou de ceras epicuticulares nas células da epiderme, como observado em $A$. schoenoprasum, pode funcionar como uma barreira à penetração do flúor no protoplasto das células epidérmicas (Kannan 1986). Os danos mais severos ocorreram associados aos estômatos, ponto de entrada do poluente na forma gasosa. A redução na espessura do mesofilo pode refletir em alterações do relevo da folha observadas ao microscópio eletrônico de varredura (Sant'Anna-Santos \& Azevedo 2007), indicando que a microscopia de luz deve ser utilizada, em conjunto com outras técnicas, para melhor caracterizar a fitotoxidade do flúor.

Não foi observada grande variação no teor de flúor, após lavagem das folhas, dentre as espécies estudadas. No entanto, visualmente, $P$. crispum foi a única das hortaliças a apresentar sintomas de fitotoxidez, demonstrando uma maior sensibilidade em comparação com as outras espécies estudadas. Sintomas em resposta ao flúor só ocorrem quando este elemento atinge níveis letais na região afetada (Coulter et al. 1985; Oliva \& Figueiredo 2005). Contudo, experimentos de laboratório, onde o poluente seja o único fator a ser considerado serão fundamentais para confirmar a hipótese de que os danos observados em P. crispum ocorreram em resposta ao poluente e não a outro agente abiótico ou biótico. Adicionalmente, nas amostras aparentemente sadias coletadas para os estudos microscópicos, os danos micromorfológicos e estruturais também foram acentuados em P. crispum. Desta forma, dentre as hortaliças avaliadas, $P$. crispum é a mais sensível a poluição em Ouro Preto, considerando-se 


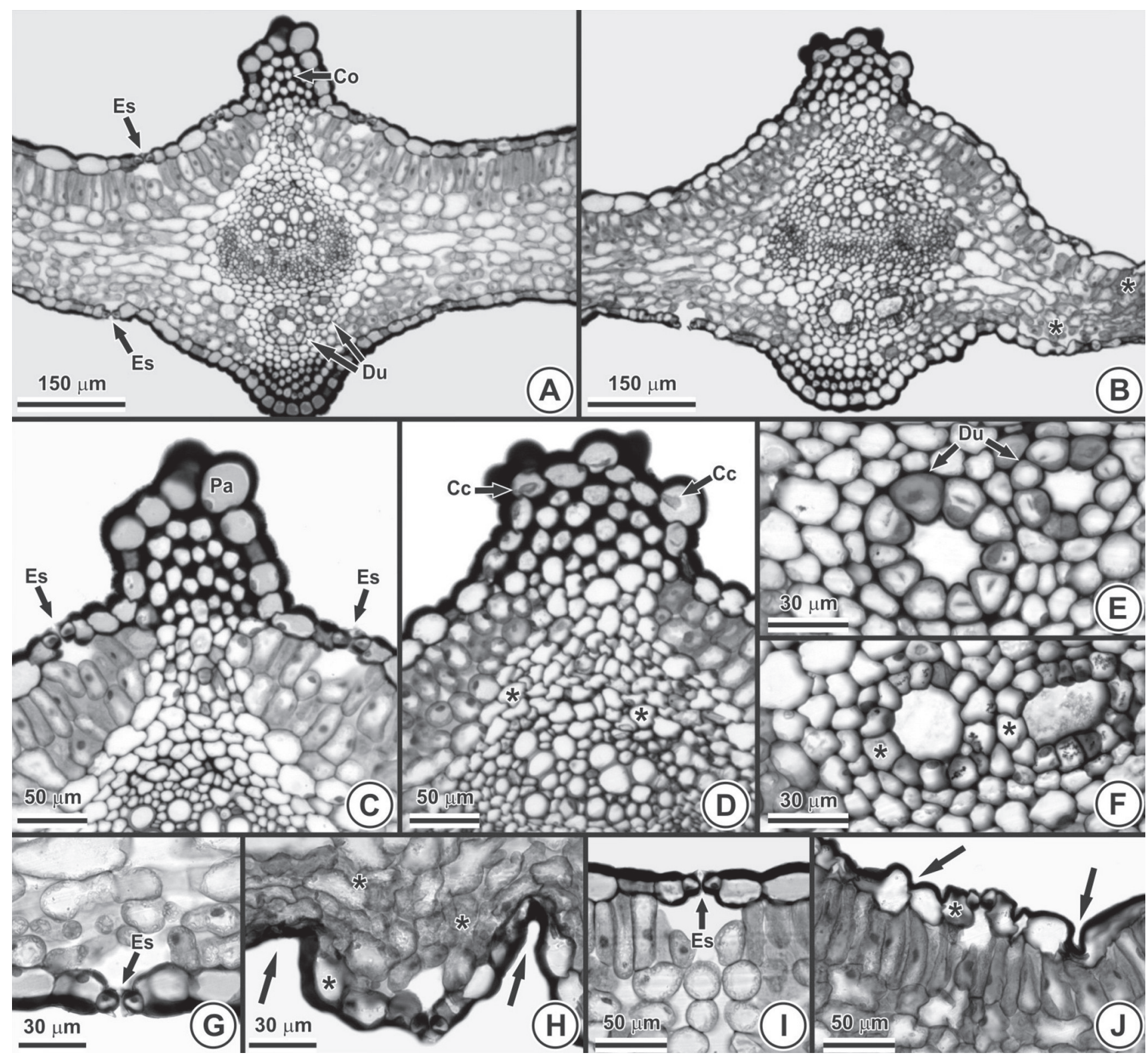

Figura 7. Anatomia foliar de Petroselinum crispum (Mill.) Mansf. (secções transversais). A, C, E, G, I. Estação referência. B, D, F, H, J. Área poluída. Estômato (Es), colênquima $(\mathrm{Co})$, ducto $(\mathrm{Du})$, papila $(\mathrm{Pa})$, formato alterado $(*)$, condensação do conteúdo celular $(\mathrm{Cc})$ e depressão na epiderme $(\rightarrow)$.

os danos macro e microscópicos. As alterações anatômicas têm sido utilizadas como subsídio para comparação da susceptibilidade entre espécies em resposta a poluição (Chaves et al. 2002; Silva et al. 2005; 2006; Sant'Anna-Santos et al. 2006a; Sant'Anna-Santos \& Azevedo 2007; Pita-Barbosa et al. 2009), mas a associação dos dados microscópicos com a sintomatologia é fundamental para a avaliação acurada dos danos (Günthardt-Goerg \& Vollenweider 2007).

Diante dos resultados, recomenda-se, que as hortaliças estudadas sejam cultivadas o mais distante possível de fontes emissoras de flúor por apresentarem, mesmo após a lavagem das folhas em água, concentrações superiores a $1 \mu \mathrm{g} \mathrm{g}^{-1} \mathrm{de}$ flúor, valor recomendado pelas autoridades sanitárias como apropriado para o consumo.

\section{Agradecimentos}

Os autores agradecem à Fapemig pela concessão de bolsa de Pós-Doutorado Júnior ao primeiro autor, ao Núcleo de Microscopia e Microanálise da UFV, pelo suporte à parte de microscopia eletrônica do trabalho e a Venceslau Santos, Dayana T. Francino, Leonardo D. Figueiredo, Taline M. Praça, Advânio I. Silva e Diego I. Rocha, pelo auxílio com a coleta e parte dos procedimentos laboratoriais.

\section{Referências bibliográficas}

Aguiar, T.V.; Sant'Anna-Santos, B.F.; Azevedo, A.A. \& Ferreira, R.S. 2007. ANATI QUANTI: software de análises quantitativas para estudos em anatomia vegetal. Planta daninha 25: 649-659.

Arndt, U.; Flores, F. \& Weinstein, L. 1995. Efeitos do flúor sobre as plantas: diagnose de danos na vegetação do Brasil. Porto Alegre, Universidade Federal do Rio Grande do Sul.

Azevedo, A.A. 1995. Ação do flúor, em chuva simulada, sobre a estrutura foliar de Glycine max (L.) Merril. Tese de Doutorado. Universidade de São Paulo, São Paulo. 

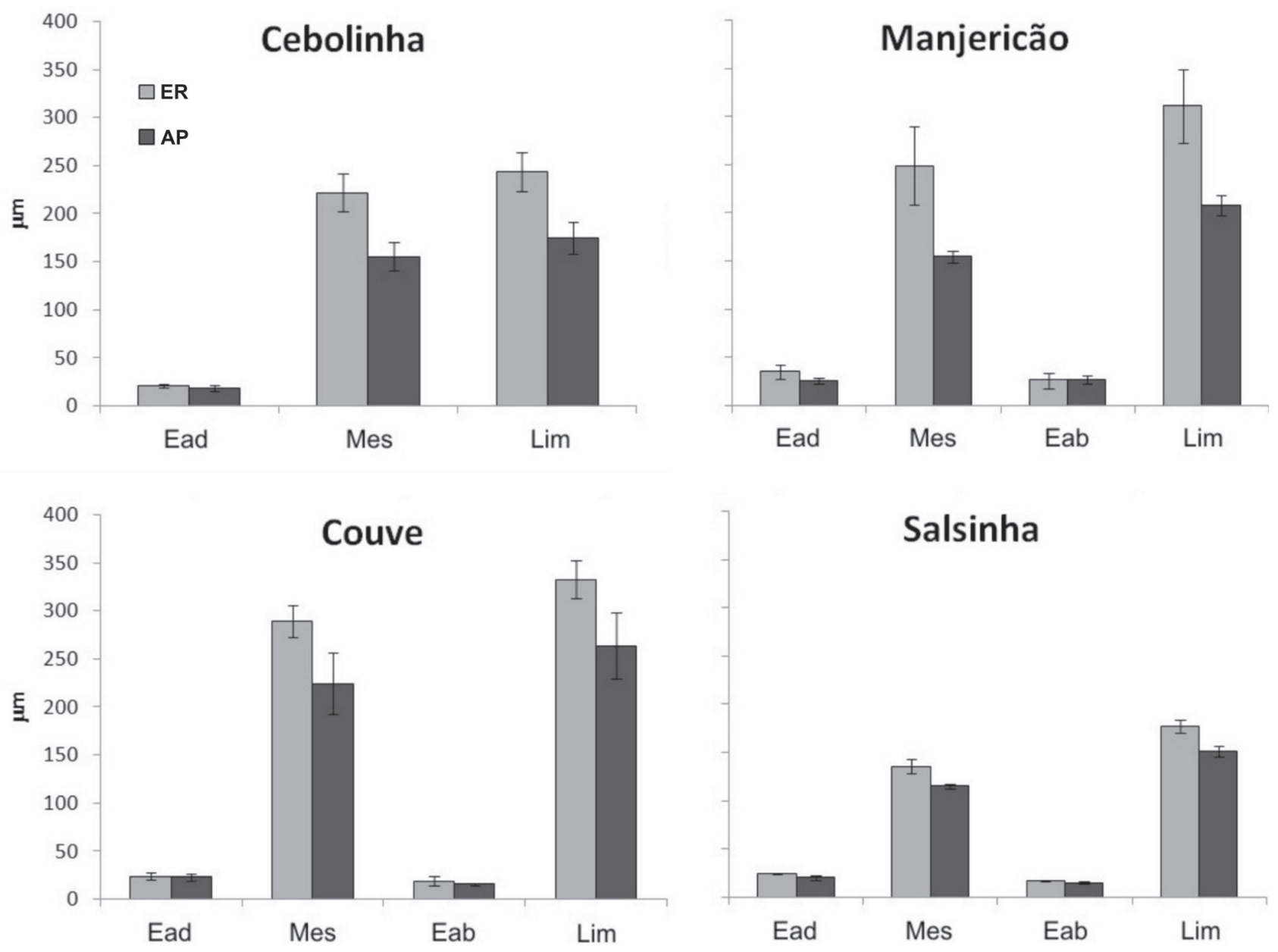

Figura 8. Espessura do limbo e altura dos tecidos das quatro espécies de hortaliças dispostas na estação referência (ER) e na área poluída (AP). Epiderme da face adaxial (Ead), mesofilo (Mes), epiderme da face abaxial (Eab), limbo (Lim). As barras verticais indicam o desvio padrão.

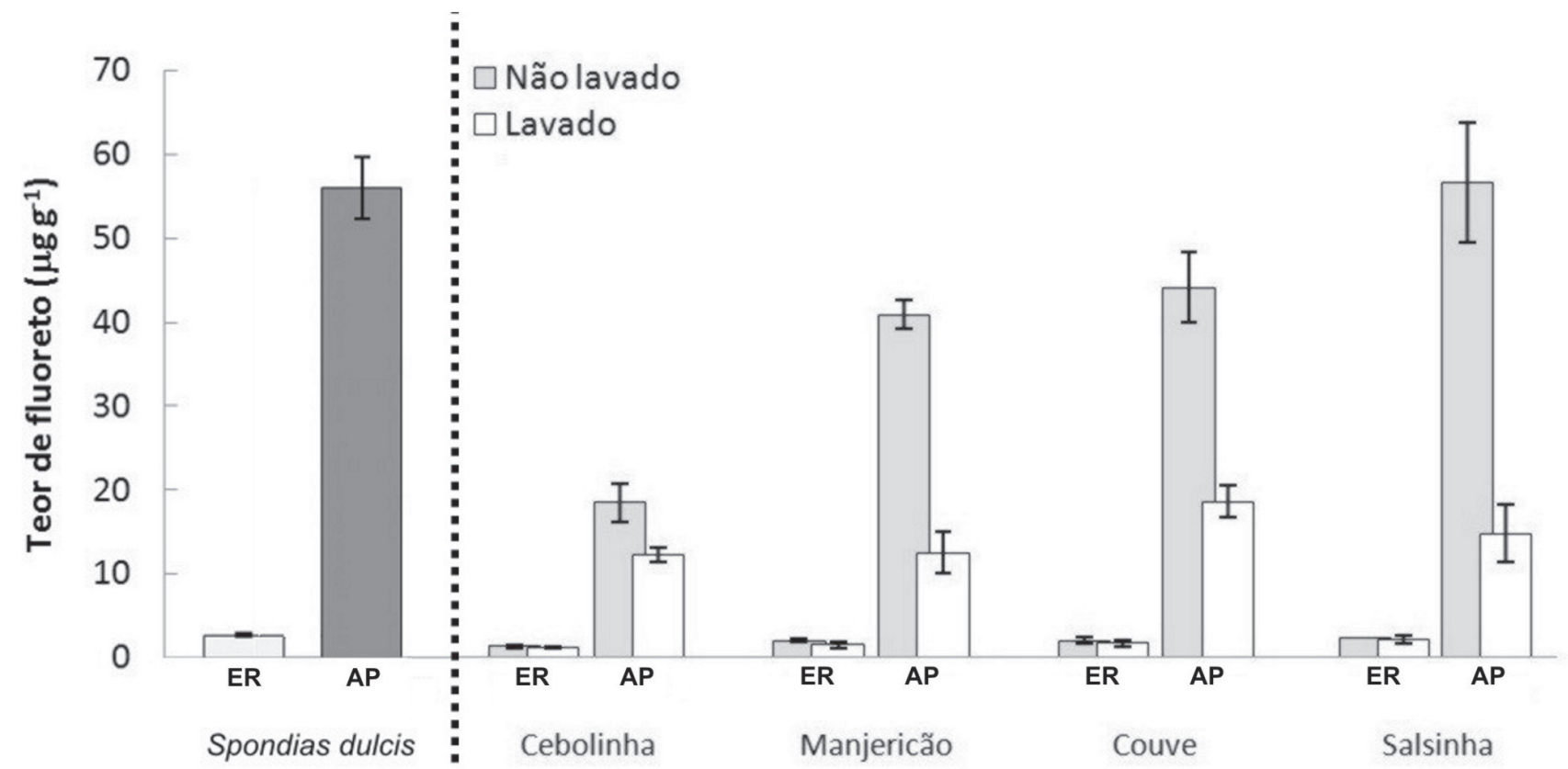

Figura 9. Teor de fluoreto em folhas de Spondias dulcis Forst. F., em comparação com as folhas lavadas e não-lavadas das hortaliças aos nove dias de exposição na área poluída (AP) e na estação referência (ER). As barras verticais indicam o desvio padrão. 
Briggs, C.L.; Morris, E.C. \& Ashford, A.E. 2005. Investigations into seed dormancy in Grevillea linearifolia, G. buxifolia and G. Sericea: Anatomy and histochemistry of the seed coat. Annals of Botany 96: 965-980.

Chaves, A.L.F.; Silva, E.A.M.; Azevedo, A.A.; Cano, M.A.O. \& Matsuoka, K. 2002. Ação do flúor dissolvido em chuva simulada sobre a estrutura foliar de Panicum maximum Jacq. (colonião) e Chloris gayana Kunth. (capim-rhodes) - Poaceae. Acta Botanica Brasílica 16: 395-406.

Coulter, C.T.; Pack, M.R. \& Sulzbach, C.W. 1985. An evaluation of the doseresponse relationship of fluoride injury to Gladiolus. Atmospheric Environment 19: 1001-1007.

Dickison, W.C. 2000. Integrative plant anatomy. Massachusetts, Harcourt/ Academic Press.

Divan Junior, A.M.; Oliva, M.A.; Martinez, C.A. \& Cambraia, J. 2007. Effects of fluoride emissions on two tropical grasses: Chloris gayana and Panicum maximum cv. Colonião. Ecotoxicology and Environmental Safety 67: 247-253.

Divan Junior, A.M.; Oliva, M.A. \& Ferreira, F.A. 2008. Dispersal pattern of airborne emissions from an aluminium smelter in Ouro Preto, Brazil, as expressed by foliar fluoride accumulation in eight plant species, Ecological Indicators 8: 454-461.

EU, 2001. European Union Risk Assessment Report: Hydrogen Fluoride, CAS-No.: 7664-39-3. 1st Priority List, vol. 8.

Fornasiero, R.B. 2001. Phytotoxic effects of fluorides. Plant Science 161: 979-985.

Fornasiero, R.B. 2003. Fluorides effects on Hypericum perforatum plants: first fieldobservations. Plant Science 165: 507-513.

Fortes, C.; Duarte, A.P.; Matsuoka, S.; Hoffmann, H.P. \& Lavorenti, N.A. 2003. Toxicidade de flúor em cultivares de milho em área próxima a uma indústria de cerâmica, Araras (SP). Bragantia 62: $275-281$

Franzaring, J.; Klumpp, A. \& Fangmeier, A. 2007. Active biomonitoring of airborne fluoride near an HF producing factory using standardised grass cultures. Atmospheric Environment 41: 4828-4840.

Garcia-Ciudad, A.; Garcia-Criado, B. \& Pontón-San Emeterio, C. 1985. Determination of fluoride in plant samples by a potentiometric method and near-infrared reflectance spectroscopy. Communications in Soil Science and Plant Analysis 16: 1107-1122.

Günthardt-Goerg, M.S. \& Vollenweider, P. 2007. Linking stress with macroscopic and microscopic leaf response in trees: New diagnostic perspectives. Environmental Pollution 147: 467-488.

Hoagland, D.R. \& Arnon, D.I. 1950. The water-culture method for growing plants without soil. (California Agricultural Experiment Station: Berkeley, CA).

Jacobson, J.S.; Weinsten, L.H.; McCune, D.C. \& Hitchcock, A.E. 1966. The accumulation of fluorine by plants. Journal of Air Pollution Control Association 16: 412-417.

Jones, S.; Burt, B.A.; Petersen, P.E \& Lennon, M.A. 2005. The effective use of fluorides in public health. Bulletin of the World Health Organization 83: 670-676.

Kannan, S. 1986. Physiology of foliar uptake of inorganic nutrients. Proceeding of the Indian Academy Science 96: 457-70.

Karnovsky, M.J. 1965. A formaldehyde-glutaraldehyde fixative of high osmolarity for use in electron microscopy. Journal of Cell Biology 27: $37-138$.

Klumpp, G.; Klumpp, A.; Domingos, M. \& Guderian, R. 1995. Hemerocallis as bioindicator of fluoride pollution in tropical countries. Environmental Monitoring and Assessment 35: 27-42.

Köeppen, W. 1948. Climatologia: com un estudio de los climas de la tierra. Pp.152-182. In: Hendrichs Pérez, P.R. (Ed.). México, D.F, Fondo de Cultura Econômica.

Larsen, S. \& Widdowson, A.E. 1971. Soil fluorine. Journal of Soil Science 22: $210-221$.

Ledbetter, M.C; Mavrodineanu, R. \& Weiss, A.J. 1960. Distribution studies of radioactive fluoride- 18 and stable fluoride-19 in tomato plants. Contribution of the Boyce Thompson Institute 20: 331-348.

Mezghani, I.; Elloumi, N.; Abdallah, F.B.; Chaieb, M. \& Boukhris, M. 2005. Fluoride accumulation by vegetation in the vicinity of a phosphate fertilizer plant in Tunisia. Fluoride 38: 69-75.
MOE, 2005. Ontario Air Standards For Hydrogen Fluoride. Ontario, Standards Development Branch Ontario, Ministry of the Environment.

Mohamed, A.H. \& Chandler, M.E. 1977. Cytological effects of sodium fluoride. The National Cancer Program Part 2, Fluoridation of Public Drinking Water, U.S. Washington, Governmental Printing Office.

O’Brien, P.P. \& McCully, M.E. 1981. The study of plants structure principles and selected methods. Melbourne, Termarcarphi Pty. Ltda.

Oliva, M.A. \& Figueiredo, J.G. 2005. Gramíneas bioindicadoras da presença de flúor em regiões tropicais. Revista Brasileira de Botânica 28: 389-397.

Peixoto, P.H.P.; Pimenta, D.S. \& Antunes, F. 2005. Efeitos do flúor em folhas de plantas aquáticas de Salvinia auriculata. Pesquisa Agropecuária Brasileira 40: 727-734.

Pita-Barbosa, A.; Sant'Anna-Santos, B.F.; Silva, K.L.F.; Azevedo, A.A. \& Rocha, D.I. 2009. Efeitos fitotóxicos do fluoreto na morfoanatomia foliar de Brachiaria brizantha (Hochst. ex A. Rich.) Stapf e Brachiaria decumbens Stapf (Poaceae). Acta Botanica Brasilica 23: 1027-1033.

Pushnik, J.C. \& Miller, G.W. 1990. The influences of elevated environmental fluoride on the physiology and metabolism of higher plants. Fluoride 23: 5-19.

Sant'Anna-Santos, B.F. 2008. Avaliação dos efeitos fitotóxicos do flúor em Spondias dulcis Forst F. (Anacardiaceae), espécie tropical sensível. Tese de Doutorado. Universidade Federal de Viçosa, Viçosa.

Sant'Anna-Santos, B.F. \& Azevedo, A.A. 2007. Aspectos morfoanatômicos da fitotoxidez do flúor em duas espécies arbóreas tropicais. Revista Brasileira de Biociências 5: 48-50.

Sant'Anna-Santos, B.F.; Silva, L.C.; Azevedo, A.A.; Araújo, J.M.; Alves, E.F.; Silva, E.A.M. \& Aguiar, R. 2006a. Effects of simulated acid rain on the foliar micromorphology and anatomy of tree tropical species. Environmental and Experimental Botany 58: 158-168.

Sant'Anna-Santos, B.F.; Thadeo, M.; Meira, R.M.S.A. \& Ascensão, L. 2006b. Anatomia e histoquímica das estruturas secretoras do caule de Spondias dulcis Forst. F. (Anacardiaceae). Revista Árvore 30: 481-489.

Sant'Anna-Santos, B.F.; Duque-Brasil, R.; Azevedo, A.A.; Silveira, A.S.; Araújo, J.M. \& Aguiar, R. 2007. Utilização de parâmetros morfoanatômicos na análise da fitotoxidez do flúor em folhas de Magnolia ovata (A. St.-Hil.) Spreng. (Magnoliaceae). Revista Árvore 31: 761-771.

Silva, L. C., Oliva, M. A., Azevedo, A. A., Araújo, J. M. 2006. Responses of restinga plant species to pollution from an iron pelletization factory. Water, Air and Soil Pollution 175: 241-256.

Silva, L.C., Oliva, M.A., Azevedo, A.A., Araújo, J. M., Aguiar, R.M. 2005. Micromorphological and anatomical alterations caused by simulated acid rain in restinga plants: Eugenia uniflora and Clusia hilariana. Water, air and soil pollution 168: 129-143.

Silva, L.C., Azevedo, A.A., Silva, E.A.M., Oliva, M.A. 2000. Flúor em chuva simulada: sintomatologia e efeitos sobre a estrutura foliar e o crescimento de plantas arbóreas. Revista Brasileira de Botânica 23: 383-391.

Treshow, M. \& Anderson, F. 1991. Plant stress from air pollution. Chichester, John Wiley and Sons.

Tuffi Santos, L.D.; Meira, R.M.S.A.; Ferreira, F.A.; Sant'Anna-Santos, B.F. \& Ferreira, L.R. 2007. Morphological responses of different eucalypt clones submitted to glyphosate drift. Environmental and Experimental Botany 59: 11-20.

Tuffi Santos, L.D.; Sant'Anna-Santos, B.F.; Meira, R.M.S.A.; Tiburcio, R.A.S.; Ferreira, F.A.; Melo, C.A.D. \& Silva, E.F.S. 2008. Danos visuais e anatômicos causados pelo glyphosate em folhas de Eucalyptus grandis. Planta Daninha 26: 9-16.

Tuffi Santos, L.D.; Sant'Anna-Santos, B.F.; Meira, R.M.S.A.; Ferreira, F.A.; Tiburcio, R.A.S. \& Silva, E.F.S. 2009. Micromorfologia foliar na análise da fitotoxidez por glyphosate em Eucalyptus grandis. Planta Daninha 27: 711-720.

VDI, 1989. VDI 2310 Part 3: Maximum immission values to protect vegetation. Maximum Immission values for Hydrogen Fluoride.VDI/ DIN-Handbuch Reinhaltung der Luft, Band 1.

Vike, E. 1999. Air-pollutant dispersal patterns and vegetation damage in the vicinity of three aluminium smelters in Norway. Science of the Total Environment 236: 75-90. 
Weinstein, L.H. 1977. Fluoride and plant life. Journal of Occupational Medicine 19: 49-78.

Weinstein, L.H. \& Davison, A.W. 2003. Native plant species suitable as bioindicators and biomonitors for airborne fluoride. Environmental Pollution 125: 3-11.

Weinstein, L.H. \& Davison, A.W. 2004. Fluorides in the environment. Oxford: CABI Publishing, $287 \mathrm{p}$.
Weinstein, L.H. 1977. Fluoride and plant life. Journal of Occupational Medicine 19: 49-78.

World Health Organization (WHO). 2002. Environmental Health Criteria 227. Fluoride. Geneva, World Health Organization.

Zhou, X.; Wu, W.; Zeng, Y.; Liao, Y.; Wang, L.; Wuhan, G.L. \& China, P.R. 2006. Industrial fluoride pollution of vegetables in Hubei province, China. Fluoride 39: 31-34.

Versão eletrônica do artigo em www.scielo.br/abb e http://www.botanica.org.br/acta/ojs 